\title{
INDICADORES DE CRÉDITO NO PERÍODO DE PANDEMIA ${ }^{1}$
}

Jéssica Fernandes de Araujo²

\section{SINOPSE}

No final de 2019, a economia brasileira apresentava certo otimismo, com reformas aprovadas, contas públicas e inflação sob controle. Com a chegada da pandemia da Covid-19, as expectativas ficaram para trás. O isolamento necessário para conter a propagação do vírus fechou escolas, comércios e empresas; o desemprego aumentou. A perda de renda do trabalhador tem dificultado a quitação de compromissos pessoais, como contas básicas e financiamentos, e as empresas lutam para não declarar falência. A injeção de capital é uma saída para enfrentar a crise sem fechar as portas. Diante desse cenário, este estudo tem como objetivo avaliar o comportamento de indicadores de crédito no Brasil durante o período da pandemia. A inadimplência caiu, os prazos foram prolongados, as taxas de juros reduzidas e o saldo da carteira continuou a crescer. Estas variaçóes podem ser explicadas pelo impulso do Auxílio Emergencial e por programas de incentivo ao crédito, lançados no primeiro semestre de 2020. Com o fim da carência dos programas do governo, o ano de 2021 pode não contar a mesma história.

Palavras-chave: indicadores de crédito; Brasil; pandemia.

\section{INTRODUÇÃO}

Em 11 de março de 2020, a Organização Mundial da Saúde (OMS) reconheceu a pandemia da Covid-19. Desde então, a saúde pública e a estabilidade econômica têm sido fortemente afetadas.

Diante do desconhecimento quase completo das características do novo vírus, as medidas de distanciamento e isolamento sociais foram formas de prevenção encontradas. Com o intuito de salvar vidas, tais açôes geraram uma crise de oferta - já que trabalhadores foram impossibilitados de frequentar postos de trabalho - e uma crise de demanda - por causa da paralisação parcial ou total de atividades produtivas. Milhares de empresas fecharam e as rendas familiares foram afetadas.

Nessas situaçôes, o fornecimento de capital é uma saída para a sobrevivência e a manutenção imediata das atividades. Para impedir que ocorra um número ainda maior de demissóes, a disponibilização de linhas de crédito ajuda com custos essenciais do empreendimento, como aluguel, salários de colaboradores, ou até mesmo investimento em um novo modelo de trabalho, como delivery e vendas virtuais.

Diversas instituições buscaram contribuir no combate à crise. As instituições financeiras (IFs) ofereceram prazos maiores e juros menores - impulsionados pela recorrente diminuição da taxa Selic. Uma das primeiras açóes do Banco Central do Brasil (BCB) foi a de adotar repactuaçóes das operaçóes de crédito pela postergação das exigências de pagamento. Na prática, isso incentivou as IFs a estender os prazos de pagamentos de dívidas.

1. DOI: http://dx.doi.org/10.38116/radar66art1

2. Pesquisadora do Subprograma de Pesquisa para o Desenvolvimento Nacional (PNPD) na Diretoria de Estudos e Políticas Setoriais de Inovação e Infraestrutura (Diset) do Ipea. E-mail: <jessica.araujo@ipea.gov.br>. 
O governo federal deu início a alguns programas de suporte já no primeiro semestre de 2020. O Auxílio Emergencial, estabelecido em abril de 2020, trouxe alívio financeiro às famílias. O Programa Nacional de Apoio às Microempresas e Empresas de Pequeno Porte (Pronampe) foi a principal linha de crédito para socorrê-las. O Banco Nacional de Desenvolvimento Econômico e Social (BNDES) montou diversas linhas, como o BNDES Crédito Pequenas Empresas, o Programa Emergencial de Acesso ao Crédito e o Programa Emergencial de Suporte a Empregos.

Perante a esse cenário, este estudou realizou uma análise retrospectiva do crédito brasileiro durante a pandemia, por meio de indicadores, como saldo da carteira ativa, prazo médio da carteira, taxa média de juros e inadimplência. O conjunto de dados advém do Sistema Gerenciador de Séries Temporais (SGS) do BCB, e varia mensalmente de janeiro de 2013 a março de 2021. Também é avaliado por pessoa física (PF) e jurídica (PJ). A título de discussão, algumas hipóteses e expectativas serão levantadas.

\section{DADOS}

O SGS 3 contém valores mensais dos principais indicadores de crédito das operaçóes do Sistema Financeiro Nacional (SFN) do Brasil. As séries temporais compreendem o período de janeiro de 2013 a março de 2021, com informações segmentadas para PF e PJ. De acordo com o Glossário de Crédito do $\mathrm{BCB},{ }^{4}$ as definiçóes para saldo, prazo, taxa de juros e inadimplência são as a seguir explicitadas.

1) Saldo da carteira ativa: somatório do saldo devedor dos contratos de crédito em final de mês. Inclui as novas concessóes liberadas no mês e a apropriação de juros pró-rata das operaçóes de empréstimos e financiamentos.

2) Prazo médio da carteira: média dos prazos de cada pagamento (em meses) ponderada pelo respectivo valor. No caso das operaçóes em atraso, são consideradas somente as carteiras com atraso até noventa dias, cujo prazo considerado na apuraçáo é de um dia.

3) Taxa média de juros: média das taxas de juros das concessóes, ponderada pelos respectivos valores desembolsados. As taxas médias dos segmentos agregados (total, PJ e PF, recurso livre e direcionado) são apuradas pelas taxas médias das modalidades, ponderadas pelos saldos médios das respectivas carteiras.

4) Inadimplência da carteira: somatório do saldo das operaçóes de crédito com atraso acima de noventa dias e não baixado para prejuízo, dividido pelo saldo total de crédito da carteira.

\subsection{Resultados}

O gráfico 1 apresenta uma visão histórica (desde 2013) dos indicadores de crédito para PJ e PF. Em destaque, os valores do início da pandemia e o do último mês analisado. A janela temporal da pandemia se inicia em março de 2020 e se prolonga até a data final observada, março de 2021.

3. Disponível em: $<$ https://bit.ly/3hC3fNb>.

4. Disponível em: <https://bit.ly/3yMR7yy>. 


\section{GRÁFICO 1}

Séries temporais dos indicadores de crédito (jan. 2013-jan. 2021)

$1 \mathrm{~A}$ - Saldo da carteira (R\$ milhões)

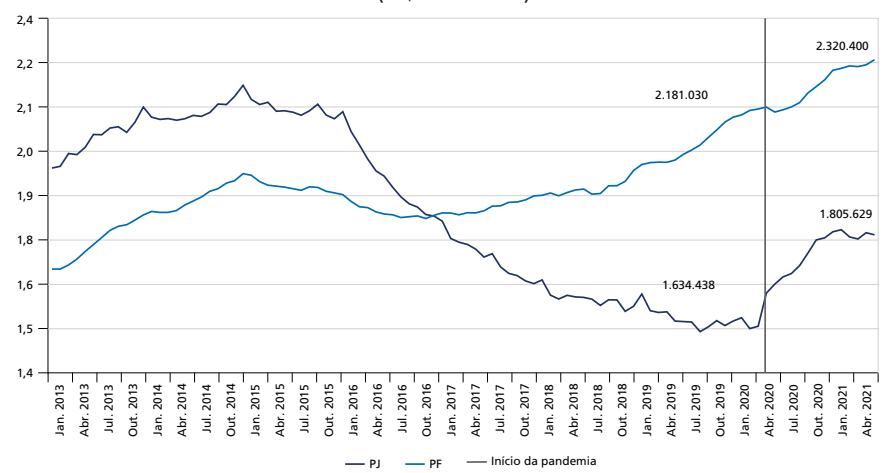

1B - Prazo médio da carteira (dias)

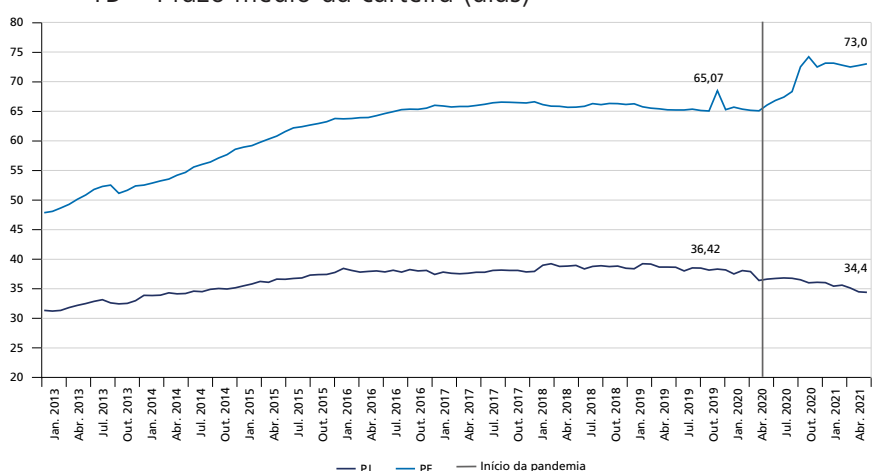

1C - Taxa média de juros (\% ao mês)

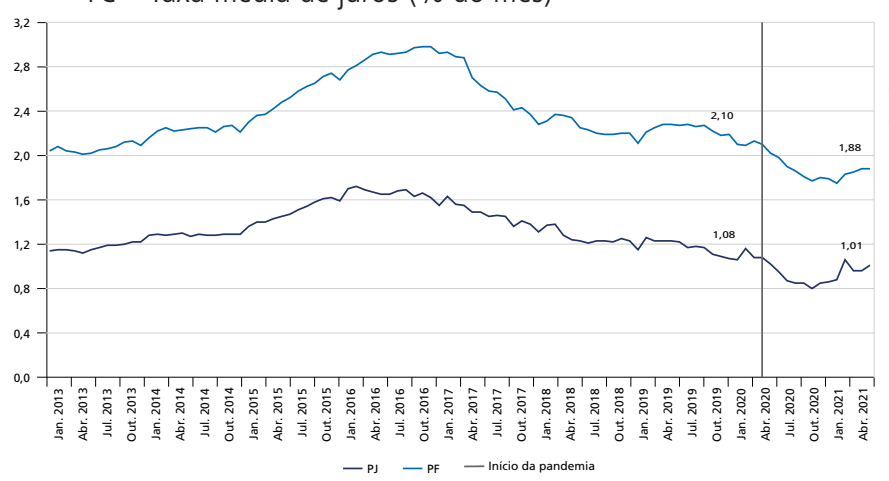

1D - Inadimplência (\%)

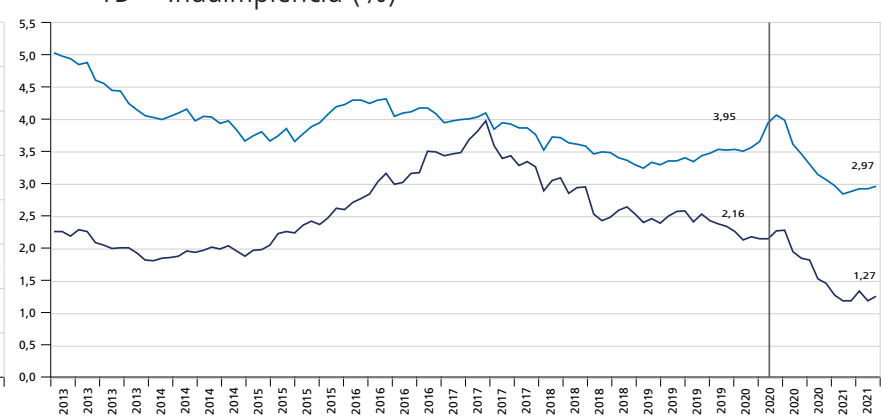

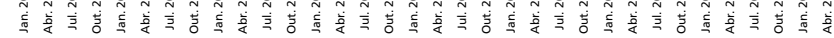

- PJ -

Fonte: Sistema Gerenciador de Séries Temporais (SGS). Disponível em: <https://bit.ly/3hC3fNb>. Acesso em: jun. 2021.

As séries de saldo (ambos os segmentos) e prazo (PF) apresentam cenário de crescimento durante o período da pandemia. A taxa de juros e inadimplência terminam em queda no ano de 2020, com retorno de crescimento em janeiro e fevereiro de 2021 - mas já em decrescimento em março de 2021. Em ambos os casos, o patamar atingido é o menor desde 2013.

O saldo ${ }^{5}$ da carteira ativa determina o valor das operaçóes de crédito no SFN. Em março de 2020, o saldo é de $\mathrm{R}$ \$ 1,6 quadrilhão para PJ e de R \$ 2,1 quadrilhóes para PF; doze meses depois, o valor atingido foi de $\mathrm{R}$ \$ 1,8 quadrilhão e $\mathrm{R} \$ 2,2$ quadrilhóes, respectivamente.

O prazo médio da carteira mensura o período médio de duração dos empréstimos. No começo da pandemia, a série do prazo apontava para 36,42 dias (PJ) e 65,07 dias (PF), em média. Em março de 2021, os valores foram de 34,47 dias e 72,74 dias, respectivamente. A reduçáo dos prazos para PJ se deu principalmente por conta da redução dos prazos dos recursos direcionados, que são os maiores para esse segmento (Santos, 2021). Esse tipo de recurso é destinado, basicamente, à produção e ao investimento de médio e longo prazos aos setores imobiliário, rural e de infraestrutura.

Em relação à taxa de juros, a trajetória foi de queda tanto para PF quanto para PJ, em todo o período da pandemia. No início de 2020, o percentual médio era de 1,08\% (PJ) e 2,10\% (PF), decaindo para 0,96\% (PJ) e $1,88 \%$ (PF) em março de 2021 .

5. A fim de expurgar o efeito inflacionário dos preços, os valores foram deflacionados pelo Índice de Preços ao Consumidor Amplo (IPCA). A data-base do índice foi março de 2021, com o objetivo de trazer uma percepção dos valores hoje. Série histórica do IPCA geral disponível em Ipeadata: <http://www.ipeadata.gov.br>. 
A inadimplência mede o percentual de pessoas e empresas em estado de noventa dias de atraso em suas dívidas. Este dado econômico é um dos mais importantes, pois determina o risco da operação de crédito. A série da inadimplência tem pico percentual atingido em abril de 2020, com o valor de 4,07\% para PFs e 2,28\% para PJs. Dali adiante, este indicador sofre uma queda acentuada, chegando em 1,20\% (PJ) e 2,97\% (PF), em março de 2021.

\section{DISCUSSÃO}

De acordo com os dados, em 2020, o saldo total de empréstimos no SFN teve crescimento ininterrupto em ambos os segmentos, PJ e PF, com destaque para o segundo. A inadimplência e a taxa de juros sofreram reduçóes. Os prazos se mantiveram para PJs e aumentaram para PFs.

Os fatores de estímulo de crédito tradicionais, como a queda na taxa básica de juros (de 4,5\% para $2 \%$ ao ano - a.a.) e a redução do compulsório (reserva obrigatória recolhida dos depósitos bancários), foram importantes para a estabilidade financeira. Além disso, no primeiro semestre de 2020, diversas medidas de apoio do governo e das IFs foram lançadas.

O Conselho Monetário Nacional (CMN) estabeleceu critérios temporários para a caracterização das reestruturaçóes de empréstimos, para fins de gerenciamento de risco de credito. ${ }^{6}$ As repactuaçóes de dívidas foram uma das primeiras medidas adotadas pelo $\mathrm{BCB}$, que, na prática, incentivou as IFs a estender os prazos de pagamentos. Desde o início da crise, cerca de um terço da carteira de crédito sofreu repactuação (BCB, 2021).

A incerteza de uma renda futura e a chegada do Auxílio Emergencial ${ }^{7}$ podem ser possíveis explicaçóes para que as famílias repensassem e revisassem gastos, priorizando o pagamento das dívidas e os bens essenciais. O Auxílio Emergencial foi pago em cinco parcelas de $\mathrm{R} \$ 600,00$, ou $\mathrm{R} \$ 1,2$ mil para mães chefes de família monoparental; depois, o auxílio foi estendido até 31 de dezembro de 2020, em até quatro parcelas de $\mathrm{R} \$ 300,00$ ou R\$ 600,00 cada.

$\mathrm{Na}$ vertente empresas, programas como o Pronampe (uma linha de financiamento exclusiva de apoio às micro e pequenas empresas), ${ }^{8}$ o Programa Emergencial de Acesso ao Crédito (Peac), ${ }^{9}$ o Programa Emergencial de Suporte a Empregos (Pese) ${ }^{10}$ e o BNDES Crédito Pequenas Empresas estimularam a roda do crédito a girar novamente.

Esses programas garantem crédito com juros menores e prazos mais dilatados a um segmento com dificuldades históricas para obtê-lo. Durante a primeira onda da pandemia, as IFs começaram a ser muito criteriosas na análise e liberação do crédito. Com o Pronampe, por exemplo, os empréstimos são facilitados, já que as IFs emprestam dinheiro a empresários tendo como garantia recursos de um fundo público. Em contrapartida, as empresas beneficiadas assumem o compromisso de preservar o número de funcionários. Diante do fato de que milhares de empresas que nunca tiveram acesso ao crédito passaram a ser incluídas no SFN, tem-se um efeito positivo no saldo da carteira ativa para PJs, que desde 2016 apresentava decrescimento.

\footnotetext{
6. Resolucão n 4.782, de 16 de março de 2020, prorrogada pela Resolução oㅜ 4.856, de 24 de setembro de 2020.

7. Lei no 13.982 , de 2 de abril de 2020.

8. Lei ํㅜ 13.999, de 18 de maio de 2020.

9. Lei no 14.042 , de 19 de agosto de 2020.

10. Lei no 14.042, de 19 de agosto de 2020.
} 
Essas medidas, no geral, são refletidas nos indicadores de inadimplência e na taxa de juros, que sofreram quedas acentuadas após março de 2020 e se encontram nos menores níveis desde 2013. Além do aumento do saldo da carteira e do prazo médio durante o período da pandemia.

No último mês em análise, março de 2021, a maioria dos programas e auxílios chegou ao fim, como é o caso dos programas no BNDES; ou foram reduzidos, como no caso do Auxílio Emergencial; ou modificados, como no caso do Pronampe. O percentual de inadimplência já apresenta um crescimento no início de 2021.

As primeiras versóes do Pronampe terminaram no fim de dezembro de 2020. Em junho de 2021, seis meses sem essa linha de crédito, o governo tornou permanente o novo Pronampe, que conta com menos recursos em relação ao anterior: tem juros mais altos $(1,25 \%$ a $6 \%$ a.a. mais a taxa Selic), prazo mais dilatado de carência (de oito para onze meses) e pagamento (de 36 meses para 48 meses). Portanto, esse novo programa pode influenciar no aumento do saldo, da taxa de juros e dos prazos em 2021.

Além disso, o Auxílio Emergencial de 2021 começou a ser pago em 6 de abril de 2021 e é limitado a uma pessoa por família. São quatro parcelas de: R \$ 150,00, para famílias de uma só pessoa; $\mathrm{R} \$ 250,00$, para famílias de duas ou mais pessoas; ou $\mathrm{R} \$ 375,00$, para mães chefes de família monoparental. Outro ponto é que a grande maioria $(84 \%)$ das operaçóes repactuadas já saiu do período de carência e voltou ao fluxo normal de pagamentos isso pode ajudar no equilíbrio e na estabilidade dos prazos médios.

\section{CONCLUSÃO}

Apesar da alta do desemprego e da baixa poupança precaucional no início da crise, os efeitos sobre a inadimplência das famílias e empresas, até aqui, são menos intensos do que se poderia prever. As taxas de juros estáo mais baixas, os prazos prolongados, o saldo da carteira de crédito em crescimento e a inadimplência no menor patamar desde 2013.

Parte dessa surpresa positiva pode estar associada a uma postura financeira mais consciente da população em meio à pandemia. Porém, é necessário que continuem a náo se comprometer com dívidas maiores do que aquelas que poderão cumprir em longo prazo.

A extensão final dos danos econômicos e sociais da Covid-19 está para ser conhecida, pois mostram-se em curso diversos programas para mitigaçáo dos efeitos da pandemia, tais como o Auxílio Emergencial, os subsídios às empresas e as postergaçóes e repactuaçóes de dívidas.

\section{REFERÊNCIAS}

BCB - BANCO CENTRAL DO BRASIL. Relatório de Estabilidade Financeira, v. 20, n. 1, abr. 2021. Disponível em: $<$ https://bit.ly/3yWR57d>.

SANTOS, F. E. de L. A. Desempenho recente do mercado de crédito. Carta de Conjuntura, n. 51, nota 13, 12 maio 2021. Disponível em: <https://bit.ly/2Tch7o2>. 